on Earth. Humans will remain morally naive so long as they live in a reference frame where one species takes itself as the center of value and values everything else relative to human reference frames. "Good for us" versus "good kind" and "good in itself" will remain a challenging issue in environmental ethics.

7. Human uniqueness. Humans as part of or apart from nature will remain a perennial issue. Humans are a unique species with unique capacities, as evidenced in language and culture, proved by their ability to place the planet in jeopardy, and proved by human concerns in environmental ethics. Placing humans in relation to the larger community of life on the planet will remain challenging, even paradoxical, with humans transcending spontaneous wild nature even as they seek to conserve such nonhuman nature.

\title{
FUTURE ENVIRONMENTAL PHILOSOPHIES AND THEIR BIOCULTURAL CONSERVATION INTERFACES
}

Ricardo Rozzi

Perhaps it would be better to speak of the future of environmental philosophies, rather than of the future of environmental philosophy. Making explicit a plurality of future trends helps prevent an "Anglo-academic" bias, and emphasizes the need for further developing environmental philosophy into at least two directions: (1) a stronger dialogical interaction with the diverse international constellation of cultural, ethnic, social, political, economic, and ecological dimensions of environmental problems; and (2) a greater integration into the transdisciplinary field of biological and cultural conservation, involving an enhanced actualization of environmental theoretical philosophy into environmental practical philosophy.

1. Toward more multi-discursive international environmental philosophies

Further developing international environmental philosophy can help 
to more precisely identify agents and causes of environmental problems, as well as their effects and victims. For instance, the focus on global climate change-and more generally global change, including other processes of rapid environmental transformation such as biotic, linguistic, and cultural homogenization-should not overlook the fact that different human communities, regions, societies, and countries are not equally responsible for such change nor suffer equally from its consequences. For example, today the highest levels of UV radiation fall on areas of Patagonia and the Antarctic Peninsula. These regions are the farthest away from the centers of CFC emissions which generate the stratospheric ozone hole found over the austral portion of the Americas. ${ }^{1}$ The incorporation of these type of regional distinctions into environmental philosophy provides the opportunity for more precise diagnoses and characterizations of environmental problems than the still-frequent generalizations stated in terms of problems between "humanity and nature." ${ }^{2}$ Such a lack of specificity is deceptive because it absolves particular responsible agents of environmental problems by referring to all humans or society in general as responsible for them.

Secondly, contrasting ecological, social, and political settings generate not only different environmental problems, but also offer a variety of viable options for solving those problems. This is a point that remains frequently overlooked within global environmental agendas. While working in conservation in Latin America, I am continuously surprised by the marked ecological and cultural singularities I find in different localities in which communities have evolved peculiar ways of understanding, valuing, and interacting with their environments. ${ }^{3}$ On the one hand, environmental philosophy would enrich itself by further incorporating this biocultural diversity. On the other hand, environmental philosophy could provide a valuable contribution to biocultural conservation by better articulating the understanding the reticulate diversity of ecological knowledge and practices that indigenous and non-indigenous old-resident communities have co-evolved with particular ecosystems and historic and cultural settings around the world.

Finally, furthering the participation of environmental thinkers of different regions and strengthening environmental philosophy networks could contribute to an international dialogue that would generate more pertinent concepts and propositions by more deeply embracing local 
social, historical, political, cultural, linguistic, and ecosystem realities. The dynamic diversity of human ecological worldviews and practices has been addressed by the field of environmental philosophy; ${ }^{4}$ however, this diversity has still not been sufficiently incorporated as part of a multi-discursive community.

2. Incorporating environmental philosophy into the theory and praxis of biocultural conservation

During the last two decades, a main goal of ecological sciences and biological conservation has been a better integration between human and natural systems. Under currently prevailing scientific approaches, such reconnection has been developed primarily through economic valuation of "ecosystem services" (see, for example, the recent landmark Millennium Ecosystem Assessment). ${ }^{5}$ Environmental philosophy has had a weak presence as compared to ecological economics in the transdiscipline of biological conservation. This weak presence is mismatched with the numerous calls made by ecologists about the need for environmental ethics, and with the frequent reference to ethical values made by international environmental conventions. For instance, the text of the Convention on Biological Diversity begins with a reference to the intrinsic value of biodiversity but it does not develop this notion at all. ${ }^{6}$ Similarly, the Millennium Ecosystem Assessment mentions the intrinsic value of biodiversity but does not develop the notion, and ends up justifying the need for its conservation in terms of economic values. Stronger participation from environmental philosophers could assist scientific teams in incorporating a broader spectrum of epistemological and ethical frameworks to understand and value human-natural systems. This represents a highly needed future direction for environmental philosophy, which is also plausible given the increasing support being provided by some science funding programs and agencies in the United States (e.g., the National Science Foundation), and Latin America (e.g., Millennium Scientific Initiative in Chile).

Among Latin American graduate students in conservation, as well as among ecologists, some government authorities, and ecotourism and protected areas managers, I perceive a growing desire to better know and incorporate philosophical notions into their approaches. By working on such conservation teams, environmental philosophers could have a signif- 
icant impact outside academic circles. At the same time, philosophical theoretical work would gain a closer attunement to empirical realities. Strengthening the notion of philosophers working in interdisciplinary and inter-institutional conservation teams with policy makers, scientists, government agencies, and non-government organizations in continuous processes where concepts and propositions are co-generated is critical to achieve the timely role that environmental philosophy should play in today's dynamic social, economic, and ecological scenarios.

\section{NOTES}

1. Kurt Jax and Ricardo Rozzi (2004). Ecological theory and values in the determination of conservation goals: examples from temperate regions of Germany, USA and Chile. Revista Chilena de Historia Natural 77: 349-366.

2. Consider, for instance, Al Gore's documentary film and book An Inconvenient Truth (http://www.climatecrisis.net/; An Inconvenient Truth: The Planetary Emergency of Global Warming and What We Can Do About It. 2006. Rodale Books: New York).

3. See Rozzi, 2001, "Éticas ambientales latinoamericanas: raíces y ramas." In Fundamentos de Conservación Biológica: Perspectivas Latinoamericanas (Primack, R., R. Rozzi, P. Feinsinger, R. Dirzo, F. Massardo), pp. 311-362. Fondo de Cultura Económica, México.

4. See, for example, J. Baird Callicott, 1997, Earth's Insights: A Survey of Ecological Ethics from the Mediterranean Basin to the Australian Outback. University of California Press: Berkeley.

5. The large scale initiative of the Millennium Ecosystem Assessment (MA) begins its series of report books by stating that the MA "was carried out between 2001 and 2005 to assess the consequences of ecosystem change for human well-being and to establish the scientific basis for actions needed to enhance the conservation and sustainable use of ecosystems and their contributions to human well-being.... The assessment focuses on the linkages between ecosystems and human well-being and, in particular, on 'ecosystem services"' (p. vii, in Ecosystems and Human Well-being: Current State and Trends, Volume 1, 2005. Rashid Hassan, Robert Scholes, and Neville Ash, editors. Island Press, Washington D.C.). The notion of ecosystem services leads the valuation approach of the whole report.

6. The Preamble of the Convention on Biological Diversity (Rio de Janeiro, Brazil, June 5,1992) begins affirming: "Conscious of the intrinsic value of biological diversity and of the ecological, genetic, social, economic, scientific, educational, cultural, recreational and aesthetic values of biological diversity and its component" (http://www.cbd.int/default.shtml). 